\title{
Modern Contraceptive Utilization and Determinant Factors among Street Reproductive-Aged Women in Amhara Regional State Zonal Towns, North West Ethiopia, 2019: Community-Based Study
}

\author{
Wondimnew Gashaw Kettema, ${ }^{1}$ Getie Lake Aynalem ${ }^{D},{ }^{2}$ Ayenew Engida Yismaw, \\ and Ayenew Worku Degu' ${ }^{1}$ \\ ${ }^{1}$ Department of Midwifery, Wollo University, Dessie City, Ethiopia \\ ${ }^{2}$ School of Midwifery, University of Gondar, Gondar City, Ethiopia
}

Correspondence should be addressed to Getie Lake Aynalem; motherliving54@gmail.com

Received 23 April 2020; Revised 4 October 2020; Accepted 12 November 2020; Published 28 November 2020

Academic Editor: Hind A. Beydoun

Copyright (c) 2020 Wondimnew Gashaw Kettema et al. This is an open access article distributed under the Creative Commons Attribution License, which permits unrestricted use, distribution, and reproduction in any medium, provided the original work is properly cited.

\begin{abstract}
Objective. Reproductive-aged women living on the street, with no doubt, are with lesser benefits of exercising their reproductive rights. Pregnancies from this marginalized population are likely to be unplanned, unwanted, and unsupported. The aim of this study, therefore, was to assess modern contraception utilization and associated factors among street reproductive-aged women in Amhara regional state zonal towns. Method. A community-based cross-sectional study was conducted among street reproductive-aged women in Amhara regional state zonal towns. A single population proportion formula was used to calculate the sample size, a similar literature-based tool adaptation was done, and a semistructured, pretested sectioned questionnaire was used. Cluster sampling technique was used to reach the study participants. Data was entered into Epi Info version 7 and exported to SPSS version 23 for analysis. A multivariable logistic regression model was fitted to control the possible effect of confounders, and finally, the independent variables were identified on the basis of OR, with 95\% CI and $p$ values less than 0.05 . Results. 604 street reproductive-aged women were interviewed in the study which make the response rate $94.2 \%$. The study revealed that current modern contraceptive utilization among the study participants was found to be $38.9 \%$. Having history of pregnancy in street life $(\mathrm{AOR}=1.70,1.1-2.7)$, having three or more live children $(\mathrm{AOR}=6.4,2.0-20.4)$, undesiring to have additional children in the future $(\mathrm{AOR}=2.7,1.4-5.1)$, mentioning three to four $(\mathrm{AOR}=2.2,1.5-3.3)$ and five or more modern contraceptive types $(\mathrm{AOR}=5.5,1.4-21.0)$, and discussion with sexual partners for contraceptive use $(\mathrm{AOR}=6.6,4.3-10.1)$ were variables significantly associated with modern contraceptive utilization. Modern contraceptive utilization among the street reproductive-aged women was low. Authors suggest that awareness creation and male partner involvement in the maternal services may be important to increase contraceptive utilization.
\end{abstract}

\section{Introduction}

Contraceptives are one of the most important health interventions of the $21^{\text {st }}$ century which is crucial in reducing rapid population growth and improving women and family health [1]. For that, the Sustainable Development Goals targeted to expand access to family planning under its target point of 3.7 [2].
Family planning saves lives and improves quality of life of women, children, and family at large. It also prevents pregnancy-related health risks in women, infant mortality, sexually transmitted infection (STI) and HIV/AIDS, and adolescent pregnancies and slows population growth $[3,4]$. Reports showed that one-quarter of maternal deaths could be averted by appropriately using contraception [5]. 
According to a 2015 worldwide report, unmet need for family planning was $12 \%$ among married women. SubSaharan Africa's unmet need for family planning (22\%) is nearly twice that of other continent's report (7-15\%). Similarly, in Ethiopia, 22\% of married women had an unmet need for family planning $[6,7]$.

Street women are a high-risk group for unintended pregnancies [8]. Almost three-fourths (73\%) of homeless women reported that their pregnancies were unintended according to the study done in Los Angeles, and half of them had a history of STD and pelvic inflammatory diseases in that study [9].

Moreover, homelessness during pregnancy increases the risk of low birth weight, small size for gestational age, and preterm birth. Although these women have strong desires to prevent pregnancy, reports show that pregnancy rates among homeless are much higher than rates among women who are housed [10-13].

Another study done in Montreal, Canada, among street women showed that there were high unintended pregnancies due to the failure of contraceptive method, carelessness for future life, drug use, and sexual abuse in street life [14].

Despite Ethiopia's contraceptive prevalence rate increasing from $29 \%$ in 2011 to $35 \%$ in 2016 , the target was $65 \%$ by 2015 which was unachieved. Previous different researches showed that women with low monthly income and unable to read and write had reported low modern contraceptive utilization as compared to rich and educated women $[3,6,15]$.

In the first half of 2018, Ethiopia has the highest number of internally displaced people than any other country, and homelessness and street residence is an escalating national problem [16].

The Ethiopian health sector gives emphasis to achieve the goal of the Health Sector Transformation Plan (HSTP) which is universal health coverage by strengthening primary health care, but street women living in informal settlements are likely excluded from formal public services, including contraceptive services [17].

A study done in Addis Ababa, capital city of Ethiopia, showed that about $36.9 \%$ of street women experienced unintentional pregnancy [18], and another study conducted in Bahir Dar town, capital city of the Amhara regional state, revealed a high rate of female rape $(24.3 \%)$ of whom $19.1 \%$ ended with unwanted pregnancy [19].

Therefore, this study was conducted to assess modern contraceptive utilization and associated factors among street reproductive-aged women in Amhara regional state zonal towns.

\section{Methods}

2.1. Study Design and Setting. A community-based crosssectional study was conducted among street reproductiveaged women in Amhara regional state zonal towns from August 15 to October 30, 2019. The Amhara regional state is one of the 10 Ethiopian national regional states. Its capital city is Bahir Dar. This region has 11 administrative zones and 140 Woredas, 80 hospitals (5 referral, 2 general, and 73 primary), 847 health centers, and 3,342 health posts according to the available data $[20,21]$. In the 2018 annual report of the Amhara National Regional State Bureau of Labor and Social Affairs, there were 2024 street reproductive-aged women in Amhara regional state [22].

2.2. Sample Size Determination and Techniques. We used a single population proportion formula using the following assumptions: proportion $(p) 34.3 \%$ (taken from street women modern contraceptive utilization done in Bahir Dar and Gondar cities) [23], 95\% confidence level, 5\% margin of error, 1.5 design effect, and $10 \%$ nonresponse rate. That is, $n=(\mathrm{Z} \alpha / 2)^{2} p(1-p) / d^{2}, n=570$.

Cluster sampling technique was used to select study participants. We used the previously divided eleven zonal towns of which five were selected by lottery method that were Dessie, Debre Tabor, Bahir Dar, Debre Markos, and Woldia towns. Then, all street women in the selected zonal towns who fulfilled the inclusion criteria and were available during the data collection period were included in the study. For this sampling procedure, we used the Amhara regional state Labor and Social Affairs annual report of 2010. Since street women are mobile and have no definite addresses, the probability of getting interviewed street women on other sites is high. To avoid interviewing more than once, participants were asked whether or not they were previously interviewed for the purpose of modern contraceptive utilization within the period of data collection. The populations for each zonal town were as follows: Bahir Dar (186), Dessie (182), Debre Markos (106), Debre Tabor (86), and Woldia (81) in which all totaled a sample size of 641 from whom 604 participated in the study.

\subsection{Operational Definitions}

(i) Modern contraceptive methods: the product or medical procedure that interferes with reproduction from acts of sexual intercourse which includes female sterilization, male sterilization, pills, the intrauterine device (IUD), injectable, implants, and condom [24]

(ii) Current modern contraceptive use: when a woman uses any of the modern contraception methods during data collection [6]

(iii) Street women: women who make their living on the street by begging, sleeping on the street or road sides which include both off-street women and on-street women [25]

(iv) On-street women: women who had no formal home (homeless) who live and sleep on streets, verandas, and balconies [25]

(v) Off-street women: women who have houses to go for sleep at night while making their living on the street or begging for money on the street and returning to their formal home at night for sleeping [25]

2.4. Data Collection Tool and Procedure. Data were collected using a semistructured questionnaire which was adapted 
from similar studies. The questionnaire was prepared in English and translated to local language (Amharic) for data collection and then translated back to English to keep the consistency of the questionnaire. Data were collected around churches in the morning, mosques on Friday lunch time, main street, and bus stations (sites where street women were sitting begging in queues).

2.5. Data Quality Control. A pretest was conducted in Gondar town on a 5\% sample size prior to the actual data collection. Training was given for fifteen data collectors and five supervisors which means three data collectors and one supervisor for each town. At the end of each day, the questionnaires were reviewed and checked for completeness, accuracy, and consistency by the supervisor and principal investigator, and corrective discussion was undertaken with data collectors.

2.6. Data Processing and Analysis. The data were entered into Epi Info version 7 and exported to SPSS version 23 for analysis. A multivariable logistic regression model was fitted to control the possible effect of confounders, and finally, the independent variables which had associations with the outcome variable were identified on the basis of OR, with $95 \%$ $\mathrm{CI}$ and $p$ values less than 0.05 .

\section{Results}

3.1. Sociodemographic Results. A total of 604 street reproductive-aged women were interviewed which gives a response rate of $94.2 \%$. Half (50.7\%) of the respondents were in the age group of 35-49 years with the median age of 35 years (IQR: 10 years). From total respondents, 382 (63.2\%) had reported that they had sexual partners. Around one in eight participants, $12.6 \%$, were on-street (homeless) women (Table 1).

3.2. Reproductive and Other Health-Related Characteristics. More than half, 340 (56.3\%), of the respondents reported that they had at least one experience of pregnancy in street life of whom 203(59.7\%) had at least one unplanned pregnancy. One in ten respondents, $70(11.6 \%)$, reported that they had a history of rape in their street life (Table 2).

3.3. Magnitude of Modern Contraceptive Utilization among the Street Women. Five in eight (61.8\%) of the study participants reported that they had used modern contraceptives in their past lifetime. Out of 382 study participants who had a sexual partner, half (49.5\%) reported that they had discussions with their partner to use modern contraceptives. Regarding current utilization of modern contraceptives, about 235 (38.9\%) (95\% CI, 35.3-42.7\%) participants were using currently. Among those who were not using modern contraceptives currently, half (50.4\%) had revealed that they did not have a plan to use in the future too.

3.4. Factors Associated with Modern Contraceptive Utilization among the Study Participants. Crudely associated variables were age, having sexual partner, family size, having history of pregnancy in street life, number of current children, time plan for having child in the future, number
TABle 1: Sociodemographic characteristics of respondents in Amhara regional state zonal towns, North West Ethiopia, $2019(N=604)$.

\begin{tabular}{|c|c|c|}
\hline Variable & $\begin{array}{c}\text { Frequency } \\
(n)\end{array}$ & $\begin{array}{c}\text { Percentage } \\
\text { (\%) }\end{array}$ \\
\hline \multicolumn{3}{|l|}{ Address } \\
\hline Bahir Dar & 177 & 29.3 \\
\hline Debre Markos & 102 & 16.9 \\
\hline Debre Tabor & 83 & 13.7 \\
\hline Dessie & 164 & 27.2 \\
\hline Woldia & 78 & 12.9 \\
\hline \multicolumn{3}{|l|}{ Age (years) } \\
\hline $15-24$ & 52 & 8.6 \\
\hline $25-34$ & 246 & 40.7 \\
\hline $35-49$ & 306 & 50.7 \\
\hline \multicolumn{3}{|l|}{ Ethnicity } \\
\hline Amhara & 596 & 98.7 \\
\hline Other $^{1}$ & 8 & 1.3 \\
\hline \multicolumn{3}{|l|}{ Religion } \\
\hline Orthodox & 537 & 88.9 \\
\hline Muslim & 67 & 11.1 \\
\hline \multicolumn{3}{|l|}{ Educational status } \\
\hline Cannot read and write & 468 & 77.5 \\
\hline Can read and write only & 54 & 8.9 \\
\hline Elementary school or above & 82 & 13.6 \\
\hline \multicolumn{3}{|l|}{ Have sexual partner } \\
\hline Yes & 382 & 63.2 \\
\hline No & 222 & 36.8 \\
\hline \multicolumn{3}{|l|}{ Residence before street life } \\
\hline Urban & 352 & 58.3 \\
\hline Rural & 252 & 41.7 \\
\hline \multicolumn{3}{|l|}{ Current residence } \\
\hline Urban & 555 & 91.9 \\
\hline Rural & 49 & 8.1 \\
\hline \multicolumn{3}{|l|}{ Sleeping place at night } \\
\hline On street & 528 & 87.4 \\
\hline Off street & 76 & 12.6 \\
\hline \multicolumn{3}{|c|}{ Knows the place where the health service is } \\
\hline Yes & 573 & 94.9 \\
\hline No & 31 & 5.1 \\
\hline \multicolumn{3}{|c|}{$\begin{array}{l}\text { Time it will take to arrive at nearby health } \\
\text { facility on foot }(N=573)\end{array}$} \\
\hline$\leq 30$ minutes & 525 & 91.6 \\
\hline$>30$ minutes & 48 & 8.4 \\
\hline \multicolumn{3}{|l|}{ Family size } \\
\hline 1 & 51 & 8.4 \\
\hline $2-3$ & 312 & 51.7 \\
\hline$\geq 4$ & 241 & 39.9 \\
\hline \multicolumn{3}{|l|}{ Duration of street life (years) } \\
\hline $0.5-5$ & 367 & 60.8 \\
\hline $6-10$ & 175 & 29.0 \\
\hline $11-15$ & 44 & 7.2 \\
\hline$>15$ & 18 & 3.0 \\
\hline
\end{tabular}

${ }^{1}$ Includes Tigray and Addis Ababa. 
TABLE 2: Reproductive and other health-related characteristics of respondents in Amhara regional state zonal towns, North West Ethiopia, $2019(N=604)$.

\begin{tabular}{|c|c|c|}
\hline Variable & $\begin{array}{l}\text { Frequency } \\
\qquad(n)\end{array}$ & $\begin{array}{l}\text { Percentage } \\
\quad(\%)\end{array}$ \\
\hline \multicolumn{3}{|l|}{ Pregnant in street life } \\
\hline Yes & 340 & 56.3 \\
\hline No & 264 & 43.7 \\
\hline \multicolumn{3}{|c|}{$\begin{array}{l}\text { Number of pregnancies in street life } \\
(N=340)\end{array}$} \\
\hline 1 & 202 & 59.4 \\
\hline 2 & 90 & 26.5 \\
\hline$\geq 3$ & 48 & 14.1 \\
\hline \multicolumn{3}{|c|}{$\begin{array}{l}\text { Plan for previous street pregnancies } \\
(N=340)\end{array}$} \\
\hline Planned & 137 & 40.3 \\
\hline Unplanned & 203 & 59.7 \\
\hline \multicolumn{3}{|l|}{ Number of alive children } \\
\hline 0 & 48 & 8.0 \\
\hline $1-2$ & 339 & 56.1 \\
\hline$\geq 3$ & 217 & 35.9 \\
\hline \multicolumn{3}{|c|}{$\begin{array}{l}\text { Time elapsed since last child } \\
\text { birth/termination (months) }(N=553)\end{array}$} \\
\hline $0-17$ & 139 & 25.1 \\
\hline $18-59$ & 289 & 52.3 \\
\hline$\geq 60$ & 125 & 22.6 \\
\hline \multicolumn{3}{|l|}{ Desire to have child in the future } \\
\hline Yes & 234 & 38.7 \\
\hline No & 370 & 61.3 \\
\hline \multicolumn{3}{|c|}{$\begin{array}{l}\text { Time of plan to have child in the future } \\
(N=234)\end{array}$} \\
\hline Within two years & 95 & 40.6 \\
\hline After two years & 139 & 59.4 \\
\hline \multicolumn{3}{|l|}{ Raped in street life } \\
\hline Yes & 70 & 11.6 \\
\hline No & 534 & 88.4 \\
\hline \multicolumn{3}{|c|}{ Number of rapes in street life $(N=70)$} \\
\hline 1 & 44 & 62.9 \\
\hline $2-4$ & 26 & 37.1 \\
\hline \multicolumn{3}{|l|}{ Have chronic illnesses/disabilities } \\
\hline Yes & 304 & 50.3 \\
\hline No & 300 & 49.7 \\
\hline \multicolumn{3}{|c|}{$\begin{array}{l}\text { Types of chronic illnesses/disabilities } \\
(N=304)^{2}\end{array}$} \\
\hline Vision impairment & 85 & 28.0 \\
\hline Problem on leg/hand & 100 & 32.9 \\
\hline Nonspecified internal problem & 60 & 19.7 \\
\hline HIV/AIDS & 47 & 15.5 \\
\hline Other $^{3}$ & 19 & 6.3 \\
\hline
\end{tabular}

${ }^{2}$ More than one response is possible. ${ }^{3}$ Includes diabetes mellitus, epilepsy, hemorrhoid, hypertension, liver cancer, pelvic organ prolapse, and tuberculosis. of contraceptives mentioned by the participant, and having discussions with sexual partners.

From the crudely associated variables, having history of pregnancy in street life, reporting three or more current children, undesiring for more children in the future, mentioning a larger number of contraceptives, and discussions with sexual partners for contraceptive use were found to be significantly associated with modern contraceptive utilization in the multivariable logistic regression analysis (Table 3 ).

\section{Discussion}

The main objectives of this study were to assess modern contraceptive utilization and associated factors among street reproductive-aged women in Amhara regional state zonal towns. According to the finding of this study, $38.9 \%$ of the participants were currently using modern contraceptives.

This current modern contraceptive utilization is comparable with findings among slum dwellers in Nairobi, Kenya $(37.9 \%)$, and street beggar women in South Ethiopia $(37.4 \%)[26,27]$.

But this finding is lower than findings in Dehradun city, India (56.8\%), an urban slum in Pune (68.5\%), and urban slum dwellers of Bangladesh (53.2\%) [26-30]. This discrepancy could be due to previous studies including traditional methods of contraceptives like the lactational amenorrhea method (LAM) which might increase the prevalence and, in addition, sociodemographic differences among the study participants.

On the other hand, this finding is relatively higher than other findings done on Dhaka street dwellers (34.5\%); Rajasthan slum dwellers (24\%); Eritrean refugee camps (26\%); migratory/slum dwellers of Karnataka, India (32\%); and North West Ethiopia (34.3\%) [23, 31-34]. It could be due to pregnant women being included previously which could decrease the prevalence of contraceptives and the time gap between the studies.

The study has revealed that history of pregnancy in street life was one of the positive predictor variables. Street women who had a history of pregnancy in street life were 1.7 times more likely to use modern contraceptives when compared with their counterparts (AOR $=1.7,95 \% \mathrm{CI}$ : $1.10,2.7)$. This finding is supported by the finding in street women in Southern Ethiopia [27]. Taking a lesson from previous sufferings of labor and child care including feeding during difficult street life might be the possible reasons to utilize modern contraceptives.

The number of current children was another predictor variable. Street women who have three or more live children currently were 6.4 times more likely to use modern contraceptives as compared to those who have no live child (AOR $=6.4,95 \%$ CI: 2.0, 20.4). This result is supported by the findings in slums in Bangladesh, Kenya, and India $[26,29,30]$. It could be that such women might have achieved their desired number of children and might be likely to use contraception.

Street women who did not want to have children in the future were 2.7 times more likely to use modern contraceptives as compared to those who wanted children within two 
TABLE 3: Bivariable and multivariable analysis of factors associated with modern contraceptive utilization among street reproductive-aged women in Amhara regional state zonal towns, North West Ethiopia, $2019(n=604)$.

\begin{tabular}{|c|c|c|c|c|}
\hline \multirow{2}{*}{ Variable } & \multicolumn{2}{|c|}{ Modern contraceptive use } & \multirow{2}{*}{ COR $(95 \%$ CI $)$} & \multirow{2}{*}{ AOR $(95 \% \mathrm{CI})$} \\
\hline & Yes & No & & \\
\hline \multicolumn{5}{|l|}{ Age } \\
\hline $15-24$ & 15 & 37 & 1 & 1 \\
\hline $25-34$ & 107 & 139 & $1.9(1.0-3.7)^{*}$ & $2.1(0.9-4.7)$ \\
\hline $35-49$ & 113 & 193 & $1.4(0.8-2.7)$ & $1.0(0.4-2.2)$ \\
\hline \multicolumn{5}{|l|}{ Have sexual partner } \\
\hline Yes & 177 & 205 & $2.4(1.7-3.5)^{* *}$ & $1.17(0.7-1.9)$ \\
\hline No & 58 & 164 & 1 & 1 \\
\hline \multicolumn{5}{|l|}{ Family size } \\
\hline Alone & 10 & 41 & 1 & 1 \\
\hline $2-3$ & 124 & 188 & $2.7(1.3-5.7)^{* *}$ & $1.2(0.4-3.0)$ \\
\hline$\geq 4$ & 101 & 140 & $2.9(1.4-6.1)^{* *}$ & $0.5(0.2-1.3)$ \\
\hline \multicolumn{5}{|c|}{ History of pregnancy in street life } \\
\hline Yes & 156 & 184 & $2.0(1.4-2.8)^{* *}$ & $1.7(1.1-2.7)^{*}$ \\
\hline No & 79 & 185 & 1 & 1 \\
\hline \multicolumn{5}{|l|}{ Number of alive children } \\
\hline No living children & 5 & 43 & 1 & 1 \\
\hline One to two & 127 & 212 & $4.1(1.7-10.0)^{* *}$ & $2.1(0.7-6.3)$ \\
\hline Three and above & 103 & 114 & $6.3(2.6-15.5)^{* *}$ & $6.4(2.00-20.4)^{* *}$ \\
\hline \multicolumn{5}{|l|}{ Desire time of child } \\
\hline Within two years & 24 & 71 & 1 & 1 \\
\hline After two years & 55 & 84 & $1.9(1.1-3.4)^{*}$ & $1.9(0.9-3.8)$ \\
\hline No more child wanted & 156 & 214 & $2.2(1.3-3.6)^{* *}$ & $2.7(1.4-5.1)^{* *}$ \\
\hline \multicolumn{5}{|c|}{ Number of contraceptives mentioned } \\
\hline$\leq 2$ & 107 & 253 & 1 & 1 \\
\hline $3-4$ & 121 & 111 & $2.6(1.8-3.6)^{* * *}$ & $0.2(0.5-3.3)$ \\
\hline$\geq 5$ & 7 & 5 & $3.3(1.0-10.7)^{*}$ & $5.5(1.4-21.0)^{*}$ \\
\hline \multicolumn{5}{|c|}{ Discussion with sexual partner } \\
\hline Yes & 128 & 61 & $6.2(4.0-9.6)^{* * *}$ & $6.6(4.3-10.1)^{* *}$ \\
\hline No & 49 & 144 & 1 & 1 \\
\hline
\end{tabular}

Keys: ${ }^{*} p$ value $<0.05$ and ${ }^{* *} p$ values $<0.01$

years $(\mathrm{AOR}=2.7,1.4-5.1)$. This is in line with literatures from Debre Birhan district and North Shewa zone $[35,36]$. It could be due to the fact that if women do not want to get pregnant, it is likely that they might use contraception.

Mentioning modern contraceptive methods was also one of the positive predictor variables for modern contraceptive utilization. Women who listed down five and above modern contraceptive types were more likely to use the modern contraception when compared with those who listed down two or less modern contraceptive types $(\mathrm{AOR}=5.5,1.4-21.0)$. The result is supported by findings from Debre Birhan district and Tigray region $[35,37]$. This could be due to women getting their preferences among the options they mentioned and being likely to use them. This indicates that awareness creation for this population is important for modern contraception utilization.
The odds of using modern contraceptives for women who had discussions with their sexual partners were 6.6 times more likely to use modern contraceptive methods than the counterparts (AOR $=6.6,4.3-10.1$ ). This is in line with studies conducted in Bale zone, Melokoza, Tigray region, rural Dembia, and North Shewa [36-40]. It could be due to the fact that discussion might increase awareness about the value of contraception and initiated the study participants to use contraceptives.

\section{Conclusion}

The study showed that modern contraceptive utilization among street women in Amhara regional state zonal towns was low when compared with the targeted contraceptive prevalence rates of Ethiopia and Amhara regional state. 
Having a history of pregnancy in street life, high number of current children, undesiring to have children in the future, mentioning more number of contraceptives, and having discussions with sexual partner for contraceptive use were predictor variables of modern contraceptive utilization among the study participants.

Reasons mentioned by the study participants for not using modern contraceptives currently were knowledge on modern contraceptives, fear of side effects, male partner opposition, unmet need on preference of modern contraceptive, inconvenient service provision time, and inaccessibility of the services.

\section{Data Availability}

The datasets used and/or analyzed during the current study are available from the corresponding author on reasonable request.

\section{Additional Points}

Limitations of This Research. We might not have possibly reached in the study participants who might be severely disabled and spending their time at their formal home, and our study lacks comparison with the general population.

\section{Ethical Approval}

First, the ethical approval was obtained from the research and publications office of University of Gondar. Support and permission letters were obtained from selected zonal city administration Labor and Social Affairs offices. Then, after explaining the purpose of the study, written consent was obtained from each participant and the identity of the respondents was anonymous. Respondents were informed that they could refuse or discontinue the participation at any time they wanted. Privacy and confidentiality of the participants were assured. The interview was mainly on sociodemographic characteristics, reproductive health-related characteristics, and awareness and utilization patterns of modern contraceptives.

\section{Conflicts of Interest}

We authors declare that we have no competing interests.

\section{Acknowledgments}

We would like to thank the University of Gondar for the ethical clearance approval. Our acknowledgement goes to the Amhara regional state zonal town Labor and Social Affairs offices for their permission letters to conduct the research. Finally, we extend our thanks to the data collectors, supervisors, and study participants.

\section{References}

[1] Y. D. Titza Tilahun, M. Bangha, C. Gatura, D. Doughman, and C. Izugbara, Contraceptive use in East Africa: what do the numbers tell us? african population and health research ceenter, 2018.
[2] O. D. S. Cf, Transforming our world: the 2030 agenda for sustainable development, 2015.

[3] A. Kesetebirhan, National guideline for family planning services in Ethiopia, Federal Democratic Republic of Ethiopia, Ministry of Health, 2011.

[4] WHO, "Family planning/contraception 2018," https://www .who.int/news-room/fact-sheets/detail/family-planningcontraception.

[5] S. Ahmed, Q. Li, L. Liu, and A. O. Tsui, "Maternal deaths averted by contraceptive use: an analysis of 172 countries," The Lancet, vol. 380, no. 9837, pp. 111-125, 2012.

[6] A. Abera, S. Tilahun, A. Sidelel, A. Habtamu, S. Merawi, and A. Abayneh, ICF CSACEa. Ethiopia demographic and health survey 2016, CSA and ICF, Addis Ababa, Ethiopia: Rockville, Maryland, USA, 2016.

[7] United Nations DoEaSA, Population division trends in contraceptive use worldwide, 2015, (ST/ESA/SER.A/349).

[8] L. Gelberg, M. C. Lu, B. D. Leake, R. M. Andersen, H. Morgenstern, and A. M. Nyamathi, "Homeless women: who is really at risk for unintended pregnancy?," Maternal and Child Health Journal, vol. 12, no. 1, pp. 52-60, 2008.

[9] L. Gelberg, B. D. Leake, M. C. Lu et al., "Use of contraceptive methods among homeless women for protection against unwanted pregnancies and sexually transmitted diseases: prior use and willingness to use in the future," Contraception, vol. 63, no. 5, pp. 277-281, 2001.

[10] D. B. Cutts, S. Coleman, M. M. Black et al., "Homelessness during pregnancy: a unique, time-dependent risk factor of birth outcomes," Maternal and Child Health Journal, vol. 19, no. 6, pp. 1276-1283, 2015.

[11] J. M. Greene and C. L. Ringwalt, "Pregnancy among three national samples of runaway and homeless youth," Journal of Adolescent Health, vol. 23, no. 6, pp. 370-377, 1998.

[12] M. Little, R. Shah, M. J. Vermeulen, A. Gorman, D. Dzendoletas, and J. G. Ray, "Adverse perinatal outcomes associated with homelessness and substance use in pregnancy," Canadian Medical Association Journal, vol. 173, no. 6, pp. 615-618, 2005.

[13] S. Kennedy, M. M. Grewal, E. M. Roberts, J. Steinauer, and C. Dehlendorf, "A qualitative study of pregnancy intention and the use of contraception among homeless women with children," Journal of health care for the poor and underserved., vol. 25, no. 2, pp. 757-770, 2014.

[14] N. Haley, V. Denis, É. Roy, and G. Gervais, Pregnancy and contraception among Montreal street-involved girls, Healthy Schools and Communities Sector, 2009.

[15] K. Asrese, T. Tilahun, and A. Mekonnen, "Demographic and socioeconomic determinants of women begging in Bahir Dar, Ethiopia," Humanities and Social Sciences, vol. 2, no. 3, p. 75, 2014.

[16] T. National, Ethiopia has highest number of internally displaced people 2018https://www.thenational.ae/world/africa/ ethiopia-has-highest-number-of-internally-displaced-peoplein-2018-1.769626.

[17] H. Wang and G. Ramana, Universal health coverage for inclusive and sustainable development, 2014.

[18] A. Akalu, Negative reproductive health (RH) outcomes appear to be associated with inadequate: Addis Abeba Universty, 2016.

[19] A. C. Misganaw and Y. A. Worku, "Assessment of sexual violence among street females in Bahir-Dar town, North West 
Ethiopia: a mixed method study," BMC Public Health, vol. 13, no. 1, p. 825, 2013.

[20] wikipedia, Amhara regionhttps://en.wikipedia.org/wiki/ Amhara_Region.

[21] Project EHSFRHFaG, HSFR/HFG end of project regional report - Amhara, 2018.

[22] region A, Annual report of Amhara national regional state bureau of labor and social affairs, 2018.

[23] B. Megabiaw, "Awareness and utilization of modern contraceptives among street women in North-West Ethiopia," BMC Women's Health, vol. 12, no. 1, p. 31, 2012.

[24] D. Hubacher and J. Trussell, "A definition of modern contraceptive methods," Contraception, vol. 92, no. 5, pp. 420-421, 2015.

[25] Unicef, A Study on street children in Zimbabwe, 2001.

[26] R. Ochako, C. Izugbara, J. Okal, I. Askew, and M. Temmerman, "Contraceptive method choice among women in slum and nonslum communities in Nairobi, Kenya," BMC women's health, vol. 16, no. 1, p. 35, 2016.

[27] S. Alemu, B. Megabiaw, A. Lette, and T. Ermeko, "A survey of contraceptive use and associated factors among street beggar women in South Ethiopia," Journal of Advances in Medicine and Medical Research, vol. 29, pp. 1-11, 2019.

[28] S. Sadhna, J. Kajal, R. Debabratta, S. Kishore, S. Gupta, and S. Kandpal, "Utilisation of maternal health services and its predictors in slum population," Acta Medica International, vol. 3, no. 1, p. 56, 2016.

[29] C. S. Taklikar, S. More, V. Kshirsagar, and V. Gode, "Prevalence of contraceptive practices in an urban slum of Pune city, India," International Journal of Medical Science and Public Health, vol. 4, no. 12, pp. 1772-1777, 2015.

[30] S. M. Kamal, "Socioeconomic factors associated with contraceptive use and method choice in urban slums of Bangladesh," Asia Pacific Journal of Public Health, vol. 27, no. 2, pp. NP2661-NP2676, 2015.

[31] T. Roy, M. T. Khatun, M. T. Hossain, and S. Rana, "Reproductive health care seeking behavior of female street dwellers of Dhaka metropolitan, Bangladesh," BANGLADESH. city, vol. 12, no. 1\&2, pp. 213-223, 2013.

[32] A. Singhal, "Utilization of maternal health services in slums of Rajasthan," International Journal of New Technology and Research, vol. 1, no. 8, 2015.

[33] D. V. Pai, Z. Anjum, A. Kumar et al., "Utilization of maternal and child health services among migratory/slum dwellers in Udupi municipality area, Karnataka, India," International Journal of Community Medicine and Public Health, vol. 5, no. 9, p. 3835, 2018.

[34] K. Gebrecherkos, B. Gebremariam, A. Gebeyehu, H. Siyum, G. Kahsay, and M. Abay, "Unmet need for modern contraception and associated factors among reproductive age group women in Eritrean refugee camps, Tigray, North Ethiopia: a cross-sectional study," BMC Research Notes, vol. 11, no. 1, p. $851,2018$.

[35] D. Muluken, B. Sileshi, W. Maereg, and Y. Muluneh, "Status of modern contraceptive use among married women in Debre Birhan district, Ethiopia," Journal of Public Health and Epidemiology, vol. 6, no. 10, pp. 316-326, 2014.

[36] A. Mohammed, D. Woldeyohannes, A. Feleke, and B. Megabiaw, "Determinants of modern contraceptive utilization among married women of reproductive age group in
North Shoa zone, Amhara region, Ethiopia," Ethiopia. Reproductive health, vol. 11, no. 1, p. 13, 2014.

[37] A. A. Medhanyie, A. Desta, M. Alemayehu et al., "Factors associated with contraceptive use in Tigray, North Ethiopia," North Ethiopia. Reproductive Health, vol. 14, no. 1, p. 27, 2017.

[38] S. Debebe, M. Andualem Limenih, and B. Biadgo, "Modern contraceptive methods utilization and associated factors among reproductive aged women in rural Dembia District, Northwest Ethiopia: community based cross-sectional study," International Journal of Reproductive BioMedicine, vol. 15, no. 6, pp. 367-374, 2017.

[39] S. S. Belda, M. T. Haile, A. T. Melku, and A. K. Tololu, "Modern contraceptive utilization and associated factors among married pastoralist women in Bale eco-region, Bale zone, South East Ethiopia," BMC Health Services Research, vol. 17, no. 1, p. 194, 2017.

[40] A. Tobe, H. Nahusenay, and D. Misker, "Factors associated with modern contraceptive service utilization among married reproductive age women in Melo Koza Woreda, southern Ethiopia," Journal of Pregnancy and Child Health, vol. 2, p. 128, 2015. 